\title{
Physical Properties, Spectroscopic, Microscopic, X-ray, and Chemometric Analysis of Starch Films Enriched with Selected Functional Additives
}

\author{
Maciej Combrzyński ${ }^{1, *(\mathbb{D})}$, Tomasz Oniszczuk ${ }^{1}$ (), Karol Kupryaniuk ${ }^{1, *}$, Agnieszka Wójtowicz $^{1}(\mathbb{D}$, \\ Marcin Mitrus ${ }^{1}{ }^{(D}$, Marek Milanowski ${ }^{1}$, Jakub Soja ${ }^{1}$, Iwona Budziak-Wieczorek ${ }^{2}{ }^{\circledR}$, Dariusz Karcz ${ }^{3}{ }^{(D)}$, \\ Daniel Kamiński ${ }^{4}{ }^{(D}$, Sławomir Kulesza ${ }^{5}{ }^{\circledR}$, Karolina Wojtunik-Kulesza ${ }^{6}$, Kamila Kasprzak-Drozd ${ }^{6}{ }^{\circledR}$, \\ Marek Gancarz ${ }^{7}$, , Iwona Kowalska ${ }^{8}$ (D) Lidia Ślusarczyk ${ }^{9}$ and Arkadiusz Matwijczuk ${ }^{9, *}$ (D)
}

1 Department of Thermal Technology and Food Process Engineering, University of Life Sciences in Lublin, Głęboka 31, 20-612 Lublin, Poland; tomasz.oniszczuk@up.lublin.pl (T.O.); agnieszka.wojtowicz@up.lublin.pl (A.W.); marcin.mitrus@up.lublin.pl (M.M.); marek.milanowski@up.lublin.pl (M.M.); jakubsoja97@wp.pl (J.S.)

2 Department of Chemistry, University of Life Sciences in Lublin, 20-950 Lublin, Poland; iwona.budziak@up.lublin.pl

3 Department of Chemical Technology and Environmental Analytics (C1), Faculty of Chemical Engineering and Technology, Cracow University of Technology, Warszawska 24, 31-155 Kraków, Poland; dariusz.karcz@pk.edu.pl

Citation: Combrzyński, M.; Oniszczuk, T.; Kupryaniuk, K.; Wójtowicz, A.; Mitrus, M.; Milanowski, M.; Soja, J.; Budziak-Wieczorek, I.; Karcz, D.; Kamiński, D.; et al. Physical Properties, Spectroscopic, Microscopic, X-ray, and Chemometric Analysis of Starch Films Enriched with Selected Functional Additives. Materials 2021, 14, 2673. https://doi.org/10.3390/ ma14102673

Academic Editor: Naozumi Teramoto with regard to jurisdictional claims in published maps and institutional affiliations.

4 Department of General and Coordination Chemistry and Crystallography, Institute of Chemical Sciences, Maria Curie-Skłodowska University in Lublin, pl. Marii Curie-Skłodowskiej 2, 20-031 Lublin, Poland; daniel.kaminski@umcs.pl

5 Department of Mechatronics, Faculty of Technical Sciences, University of Warmia and Mazury in Olsztyn, Oczapowskiego 11, 10-710 Olsztyn, Poland; slawek.kulesza@gmail.com

6 Department of Inorganic Chemistry, Medical University in Lublin, 20-059 Lublin, Poland; k.wojtunik@o2.pl (K.W.-K.); kamilakasprzakdrozd@gmail.com (K.K.-D.)

7 Institute of Agrophysics Polish Academy of Sciences, Doświadczalna 4, 20-290 Lublin, Poland; m.gancarz@ipan.lublin.pl

8 Department of Biochemistry and Crop Quality, Institute of Soil Science and Plant Cultivation, State Research Institute, 24-100 Puławy, Poland; ikowalska@iung.pulawy.pl

9 Department of Biophysics, University of Life Sciences in Lublin, Akademicka 13, 20-950 Lublin, Poland; lidia.slusarczyk@up.lublin.pl

* Correspondence: maciej.combrzynski@up.lublin.pl (M.C.); karol.kupryaniuk@o2.pl (K.K.); arkadiusz.matwijczuk@up.lublin.pl (A.M.)

Abstract: Biodegradable materials are used in the manufacture of packaging and compostable films and various types of medical products. They have demonstrated a large number of potential practical applications in medicine and particularly in the treatment of various cardiac, vascular, and orthopedic conditions in adults as well in children. In our research, the extrusion-cooking technique was applied to prepare thermoplastic starch (TPS), which was then utilized to obtain environmentally friendly starch-based films. Potato starch was the basic raw material exploited. Polyvinyl alcohol and keratin were used as functional additives in amounts from 0.5 to $3 \%$, while $20 \%$ of glycerol was harnessed as a plasticizer. The processing of the thermoplastic starch employed a single screw extruder-cooker with an L/D ratio of 16 . The film blowing process was carried out using a film-blowing laboratory line with $\mathrm{L} / \mathrm{D}=36$. FTIR Spectroscopy was applied for the assignment of the prominent functional groups. The results showed that the processing efficiency of thermoplastic starch with functional additives varied depending on the level of polyvinyl alcohol and keratin addition. Moreover, the FTIR data correlated with the changes in the physical properties of the tested films. The analysis of FTIR spectra revealed several changes in the intensity of bands originating from stretching vibrations characteristic of the $-\mathrm{OH}$ substituent. The changes observed depended on the presence/lack of the hydrogen bonding occurring upon interactions between the starch molecules and the various additives used. In addition, notable changes were observed in bands assigned to glycoside bonds in the starch. 
Keywords: thermoplastic starch with functional additives; extrusion-cooking; biopolymer films; molecular spectroscopy and chemometric analysis; AFM; nanomechanical mapping and X-ray

\section{Introduction}

The bioplastics market, which started to emerge not even 20 years ago, is growing rapidly and has already reached impressive production volumes. It is estimated that the global production of plastics reached over 400 million tons in 2015. In 2018, the global production of plastics totaled 359 million tons [1]. Despite the economic slowdown of 2009, which seriously undermined the chemical and plastics industries, demand for bioplastics was on the rise, both in Europe (from 5\% to 10\%), as well as in North America and Asia. In 2017, it was estimated that the global bioplastics manufacturing capacity would increase from 2.05 million tons to approx. 2.44 million tons by 2022. In a 2009 report, European Bioplastics envisaged the growth of the biopolymer market by an average of $19 \%$ yearon-year between 2007 and 2020. The use of polymers, such as PLA (polylactic acid) and PHAs (polyhydroxyalkanoates), has the greatest impact on the ever-higher supply of biodegradable plastics. The largest market for biodegradable polymers is Europe. Within the European continent, the greatest developments in biopolymers are seen in Germany, Austria, Benelux, and Scandinavia [2].

Biocomposite materials, notably biodegradable and bio-based, are practically absent on the Polish market. Their potential has not been recognized and, above all, not used. The reasons behind this are: the low worldwide spread of biopolymer composites, lack of adequate information on possible applications, presuppositions concerning the processing, and the unsatisfactory properties of these materials. The large production and consumption figures in Europe are mainly attributable to the legislative setting, yet it is the United States that has the largest production capacity. This is thanks to the PLA manufacturing facility run by NatureWorks LLC, although not exploited to its full capacity. Given the impressive development in technology in recent years and the competitiveness of bioplastics, the range of products that can be made from or with biocomposites is already remarkable and new opportunities are already around the corner. Biopolymer composite materials can be used mainly as products with a short life cycle, for example, packaging, containers, buckets, boxes, films for mulching, biodegradable pots, products for the catering industry, etc. What is more, biopolymers with high mechanical properties and extended useful life can be used as a cover for composites used as construction materials [3].

Such polymers provide a reasonable alternative to traditional synthetic materials, the disposal of which harms the natural environment. Packaging and packaging waste is governed by a law (Journal of Laws of 2013, item 888, as amended, and Directive (EU) 2018/851 of the European Parliament and of the Council) that demands that certain levels of waste be subjected to recovery, including recycling. Biocomposites are composite materials with at least one "bio" component. Therefore, biocomposites are also petrochemical polymers, biopolymers filled with natural fibers, and biopolymers with synthetic fibers. One group of biodegradable bio-based polymers are those produced from plants, among them are polysaccharides obtained by fractionation, for example, starch obtained from potatoes, maize, rice, or wheat [4].

The production of starch polymers begins with the separation of starch from the raw material. To obtain thermoplastic starch, the crystalline structure of its grains is destroyed by extrusion with the addition of a plasticizer (e.g., glycerol). Thermoplastic starch (TPS) often contains more than $70 \%$ fully biodegradable starch. This material exhibits moderate mechanical properties. Consequently, most starch-based polymers are thermoplastic mixtures of starch with other polymers. Starch polymers have also been proven to be easy to process. They can be made into end products by using slightly modified standard thermoplastic processing equipment, mainly by extrusion, injection, hot forming, blowing, or foaming. This material, however, has certain disadvantages, one of 
them being reduced resistance to solvents, especially water [5]. Hence, of great importance is the use of appropriate functional additives that alter the properties of pure thermoplastic starch. Besides functional additives based on petrochemicals, there are also natural and biodegradable materials that, when used in a reasonable manner, can add certain desired characteristics to any final product [6,7]. These are, for example, polyvinyl alcohol and keratin [8,9].

The aim of the research was an in-depth analysis of both the thermoplastic starch extrusion process and the physicochemical, spectroscopic, and surface properties, as well as the internal structure of new types of biodegradable films with various functional additives. For this purpose, the following were engaged: infrared spectroscopy (Fourier-transform infrared spectroscopy, FTIR) combined with PCA (principal component analysis) and HCA (hierarchical clustering analysis), X-ray diffraction (XRD analysis), and detailed surface studies employing AFM (atomic force microscopy).

The final surface texture carries a unique imprint of complex processes occurring simultaneously in the bulk and at the interfacial boundaries of solids. Hence, in-depth, multi-aspect characterization of the surface needs to be carried out to assess the effective exploitation of the functional properties of novel materials. Atomic force microscopy (AFM) proved to be an extremely useful and accurate method in that matter according to results reported in such fields as metallurgy and ceramics [9-11], biology and medicine [12-14], environmental studies [15], and others. This technique was also successfully applied to polymers, for example, to study temperature-induced changes in the surface topography of low-density polyethylene (LDPE) [16]. To our best knowledge, there are no studies concerning such a form of properties evaluation of biopolymers based on potato starch.

\section{Materials and Methods}

Potato starch of the Superior Standard type (PEPEES S. A., Łomża, Poland) was used in the study. The moisture content of the starch was $15.6 \%$ and the $\mathrm{pH}$ was 7.2. Polyvinyl alcohol PVA (Avantor-POCH S.A., Gliwice, Poland) was assessed for employment as a functional additive in the amount of $0.5,1.0,2.0$, and $3.0 \%(w / w)$. PVA. This has a melting temperature of $160-200{ }^{\circ} \mathrm{C}$ and is an odor-free white powder with a density of $1.2-1.3 \mathrm{~g} \cdot \mathrm{cm}^{-3}$. The application of Keratin (Noble Health, Radom, Poland) was also established as a functional additive in the amount of $0.5,1.0$, and $1.5 \%(w / w)$. During bio-granulate production, a plasticizer-glycerol of 99.5\% purity (Brenntag Polska sp. z o.o., Kędzierzyn-Koźle, Poland) was added in the amount of $20 \%(w / w)$.

In order to homogenize each blend, the samples (shown in Table 1) were left in sealed plastic bags for $24 \mathrm{~h}$. Before the extrusion-cooking process began, the raw material blends were re-mixed.

Table 1. Raw material mixtures used in the tests.

\begin{tabular}{ccccc}
\hline Sample Code & Potato Starch (\%) & Glycerol (\%) & Polyvinyl Alcohol (\%) & Keratin (\%) \\
\hline SGA-I & 79.0 & 20 & 1.0 & 0 \\
SGA-II & 78.0 & 20 & 2.0 & 0 \\
SGA-III & 77.0 & 20 & 3.0 & 0 \\
SGAK-I & 78.0 & 20 & 1.0 & 1.0 \\
SGAK-II & 79.0 & 20 & 0.5 & 0.5 \\
SGAK-III & 77.0 & 20 & 1.5 & 1.5 \\
\hline
\end{tabular}

SGA-mixture with starch, glycerol, and polyvinyl alcohol addition; SGAK—-mixture with starch, glycerol, polyvinyl alcohol, and keratin addition.

\subsection{Process of Obtaining Starch-Based Film}

The starch-based films (Figure 1) were produced using a two-step process:

Step 1: Biopolymer granulates of TPS were obtained using extrusion-cooking equipmenta modified single screw extrusion-cooker TS-45 (ZMCh Metalchem Gliwice, Poland). The TPS was processed with a screw speed of $100 \mathrm{rpm}$ and with a circular forming die with $3 \mathrm{~mm}$ 
of diameter. Extrusion-cooking was carried out at a temperature range from 60 to $100{ }^{\circ} \mathrm{C}$. The product was shaped using a high-speed knife mounted at the head. Its rotational speed was adapted to the desired dimensions of the extrudates, that is, a diameter of approx. $3 \mathrm{~mm}$. The product obtained in the process was stabilized at ambient temperature in a shelf dryer. After cooling, the extrudates were stored in bags and sampled for further tests.

Step 2: Starch-based films were generated from the above-mentioned granulates using a film-blowing laboratory line produced by SAVO Ltd. Co., Warsaw, Poland (Figure 2). The film blowing process was carried out with a plastic extruder with $\mathrm{L} / \mathrm{D}=36$, and with a screw speed from 30 to $100 \mathrm{rpm}$. During extrusion, a die-mold with a nozzle diameter of $80 \mathrm{~mm}$ and a working slit of $0.6 \mathrm{~mm}$ was used.

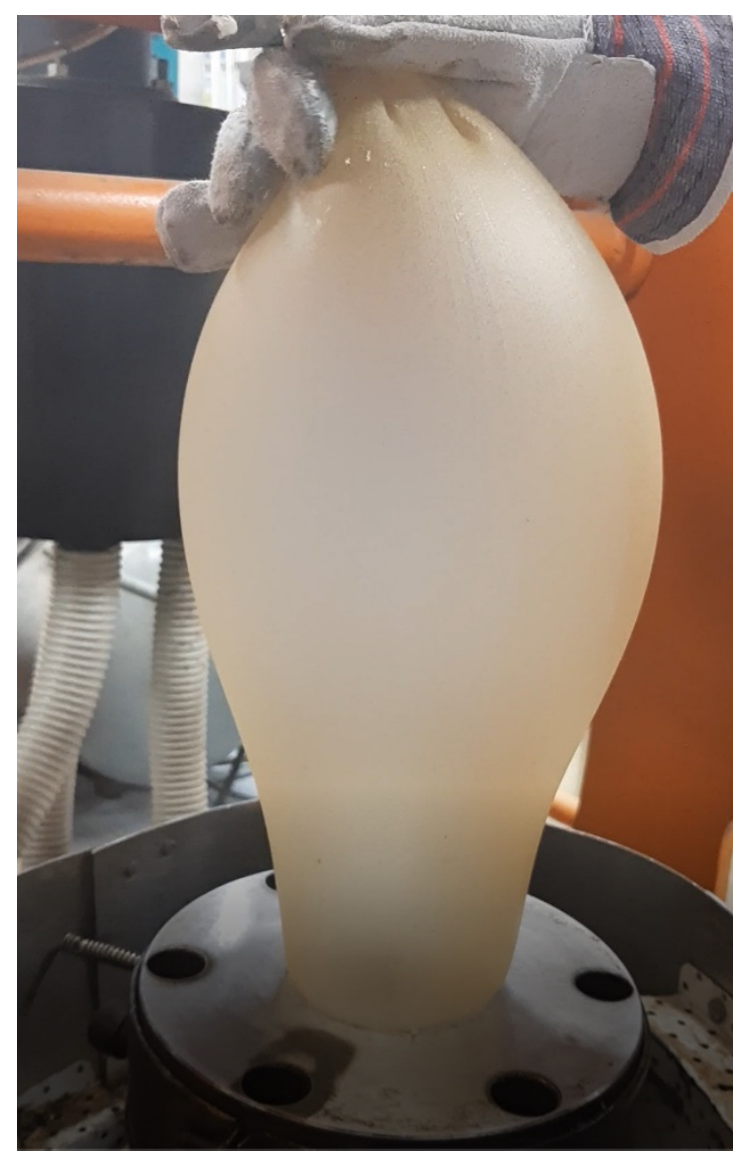

Figure 1. Starch-based film with functional substances blowing in laboratory.

For the extrusion-cooking process, drive parameters (including load) were taken into account, as well as the efficiency of extrusion-cooking for the individual raw material blends. The efficiency of extrusion-cooking of starch-based materials was determined by the sampling of extrudates at a specific time. The efficiency was calculated according to the formula [17].

$$
\mathrm{Q}=\frac{\mathrm{m}}{\mathrm{t}}\left(\mathrm{kg} \mathrm{h}^{-1}\right)
$$

where:

Q: process efficiency $\left(\mathrm{kg} \mathrm{h}^{-1}\right)$

$\mathrm{m}$ : mass of extrudate obtained in the measurement $(\mathrm{kg})$,

$\mathrm{t}$ : time of measurement $(\mathrm{h})$.

Energy intensity was determined based on the specific mechanical energy (SME) value, by exploiting the formula proposed by Ryu and $\mathrm{Ng}$ [18].

$$
\mathrm{SME}=\frac{\mathrm{nPO}}{\mathrm{n}_{\mathrm{m}} \mathrm{Q}}\left(\mathrm{kWh} \mathrm{kg}^{-1}\right)
$$


where:

SME: Specific Mechanical Energy $\left(\mathrm{kWh} \mathrm{kg}^{-1}\right)$

$\mathrm{n}$ : extruder-cooker screw speed $\left(1 \mathrm{~s}^{-1}\right)$,

$\mathrm{n}_{\mathrm{m}}$ : extruder-cooker nominal speed $\left(1 \mathrm{~s}^{-1}\right)$,

O: drive load v. maximum load (\%),

P: nominal power $(\mathrm{kW})$,

Q: extrusion-cooking efficiency $\left(\mathrm{kg} \mathrm{h}^{-1}\right)$.

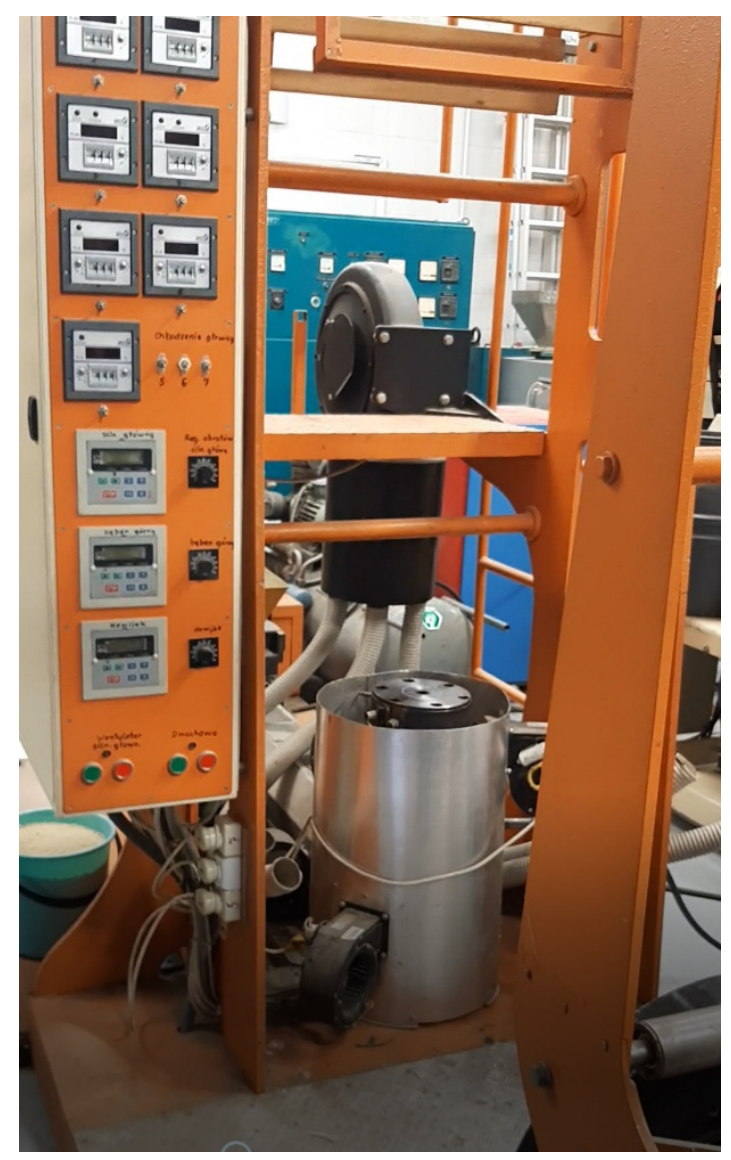

Figure 2. Film-blowing laboratory line.

\subsection{AFM Nanomechanical Mapping}

Maps of the surface properties of the extruded biopolymer films were examined on both sides of the samples by means of the application of the Atomic Force Microscopy method (AFM), using a Multimode 8 instrument (Bruker, Ettlingen, Germany). The measurements were carried out in tapping mode, as this provided direct control of the tipsample interaction so that the maximum repulsive force did not exceed $500 \mathrm{pN}$. Each image covered a $1 \times 1 \mu \mathrm{m}^{2}$ scan area, was taken as a $256 \times 256$ step, and corresponded to a lateral resolution slightly below $4 \mathrm{~nm}$. Apart from the topography, however, captured data were also helpful in studying variations in the pseudo-Young's modulus and tip-surface adhesion force that both contributed to the nanomechanical properties of the surface. AFM measurement was done by employing a silicon-scanning probe (TAP150GD-G, BudgetSensors, Sofia, Bulgaria) with a nominal spring constant of $5 \mathrm{~N} / \mathrm{m}$, resonance frequency of $150 \mathrm{kHz}$, and tip radius of $10 \mathrm{~nm}$. Prior to any analysis, height images were plane-fitted in order to remove surface tilt and then flattened row by row to level the neighboring lines in the image. 


\subsection{FTIR Spectroscopy}

The ATR-FTIR spectra were recorded within the range of 4000 and $400 \mathrm{~cm}^{-1}$ with the use of a Vector 3300 spectrometer (Bruker Optik GmbH, Ettlingen, Germany). The measurements were carried out in solvents at a temperature of $23^{\circ} \mathrm{C}$ using a $\mathrm{ZnSe}$ trough ( $45^{\circ}$ cut, yielding 10 internal reflections) crystal plate for liquids and were backgroundcorrected $[19,20]$.

\section{Multivariate Analysis}

\subsection{Principal Component Analysis (PCA)}

Principal component analysis (PCA) is one of the most commonly utilized statistical data reduction methods. The purpose of this method is to decompose the original set of variables into a new set of uncorrelated variables called principal components (PCs), that retain as much of the information in the original variables as possible [21,22]. The general PCA model can be expressed as:

$$
\mathrm{X}=\mathrm{TP}^{\mathrm{T}}+\mathrm{E}
$$

where $\mathrm{X}$ is the data matrix to be analyzed, $\mathrm{T}$ is called the score matrix, $\mathrm{P}$ is the loading matrix, and $\mathrm{E}$ is the residual, respectively.

\subsection{Hierarchical Clustering Analysis (HCA)}

Another applicable chemometrics method is hierarchical clustering analysis $[23,24]$. HCA is an exploratory data analysis that is used for detecting similarities in the variables set and for classifying them into clusters. Graphical representation of results is a tree-based representation of the objects, deemed a "dendrogram".

Multivariate analyses, including principal component analysis (PCA) and hierarchical cluster analysis (HCA), were performed for the FTIR spectra. Grams/AI 8.0 software (Thermo Scientific, Waltham, MA, USA) was applied for multi-point baseline correction, Savitzky-Golay smoothing, as well as $\mathrm{Y}$ offset correlation, and points were set to zero prior to the analysis. The PCA and HCA analyses were performed within the range of $3700-600 \mathrm{~cm}^{-1}$ and $1800-600 \mathrm{~cm}^{-1}$. In the hierarchical cluster analysis, the Ward method and average linkage distance between the pairs of samples were used as linkage criteria. Pearson correlation distance between the pairs of samples was assessed as a distance measure. Statistica 13 software (TIBCO Software Inc., Palo Alto, CA, USA) was applied for chemometrics analysis. Samples were allocated into six groups in relation to Table 1.

\subsection{XRD Analysis}

Films that were $1 \mathrm{~mm}$ thick with dimensions of $10 \times 10 \mathrm{~mm}$ were analyzed by applying the powder X-ray diffraction technique, by employing an Empyrean (PANalytical, Warsaw, Poland) diffractometer with a $\mathrm{Cu}$ anode as a source for $\mathrm{CuK} \alpha \mathrm{X}$-ray radiation $(\lambda=1.5406 \AA)$. This instrument was equipped with a PIXcel3D detector. All samples were measured over a $2 \theta$ range of 4 to $43.5^{\circ}$, with a step size of $0.26^{\circ}$ and an exposure time per step of $12.6 \mathrm{~s}$. Diffraction data were assessed utilizing WAXFIT [25] software to determine the degree of crystallinity. All data were normalized, background-corrected (hyperbolic function), and fitted to a model containing 15 Gauss-Cauchy functions that approximate the crystalline phase and 1 function that approximates the amorphous phase. The degree of crystallinity was presented as a ratio between surface areas under the curves of the crystalline phase to the sum of the crystalline and amorphous phases.

\section{Results and Discussion}

\subsection{Results and Discussion of Extrusion-Cooking Processing}

Table 2 provides a listing of the measured results for the efficiency and the energy consumption of the extrusion-cooking process of potato starch with the addition of functional substances. With most of the blends applied, the process was exceptionally constant 
and free from disturbances that would trigger changes in the energy consumption of the process.

Table 2. The process efficiency and the specific mechanical energy of the thermoplastic starch extrusion-cooking process with the addition of functional substances.

\begin{tabular}{cccc}
\hline Parameter & Polyvinyl Alcohol [\%] & Keratin [\%] & Results \\
\hline & 1.0 & 0 & $28.9 \pm 0.2$ \\
Efficiency $\left(\mathrm{kg} \mathrm{h}^{-1}\right)$ & 2.0 & 0 & $29.6 \pm 0.2$ \\
& 3.0 & 0 & $31.2 \pm 0.2$ \\
& 0.5 & 0.5 & $29.2 \pm 0.2$ \\
& 1.0 & 1.0 & $30.2 \pm 0.2$ \\
& 1.5 & 0 & $31.8 \pm 0.2$ \\
\hline \multirow{2}{*}{ SME $\left(\mathrm{kWh} \mathrm{kg}^{-1}\right)$} & 1.0 & 0 & $0.14 \pm 0.02$ \\
& 2.0 & 0 & $0.18 \pm 0.02$ \\
& 3.0 & 0.5 & $0.22 \pm 0.02$ \\
& 0.5 & 1.0 & $0.18 \pm 0.02$ \\
& 1.0 & 1.5 & $0.08 \pm 0.02$ \\
\hline
\end{tabular}

During the manufacturing, it was observed that an increase in polyvinyl alcohol and keratin content resulted in increased efficiency of extrusion-cooking. Higher values were also obtained for samples containing the two functional additives. The highest efficiency was reported for a mixture of starch with the addition of $1.5 \%$ of both polyvinyl alcohol and keratin $\left(31.8 \mathrm{~kg} \mathrm{~h}^{-1}\right)$. The observed relationships resemble the results achieved during the extrusion-cooking of thermoplastic starch with functional additives, including PVA [26]. The results also confirm that the efficiency of the extrusion-cooking improved along with the amount of the additive.

When polyvinyl alcohol was added, higher SME was observed as the amount of PVA in the blend was raised. This result is consistent with what other researchers have observed [27]. In contrast, the opposite relationship was reported when PVA was combined with keratin. With an increasing amount of polyvinyl alcohol and keratin, the SME of the extrusion-cooking process decreased. Lower energy consumption values of extrusioncooking were noted for samples containing both functional additives. The lowest energy consumption was reported for a mixture of starch with the addition of $1.5 \%$ of both polyvinyl alcohol and keratin $\left(0.08 \mathrm{kWh} \mathrm{kg}^{-1}\right)$. It is worth noting that with these processed blends, the process was extremely stable and constant, which is also evidenced by load tests of the plasticizing system in relation to the extruder-cooker drive.

\subsection{Results and Discussion of AFM Nanomechanical Imaging}

Figure 3 shows example AFM images of surfaces on both sides of the biopolymer thin foil made with a minor addition of keratin (SGAK-I). The presented images reveal differences in the specific size of dominant structural patterns likely caused by differences in the cooling rate of the material on both sides of the foil. Surface A exhibits the internal structure of the foil during film blowing, which was cooled down with pressured air from a compressor, while surface B shows the external structure coming out from the forming die, as shown in Figure 1. The surface of side A exhibits significant waviness because of the irregular airflow during blowing and a faster cooling rate was then observed at the external surface. Here, the horizontal period of the height variations approaches half a micrometer and is disturbed by randomly placed irregular particles around two orders of magnitude smaller. Side B was found to be significantly flatter, and slight fluctuations of the surface heights occur within the range of single nanometers. Similar observations can be made for the remaining films in this study. 

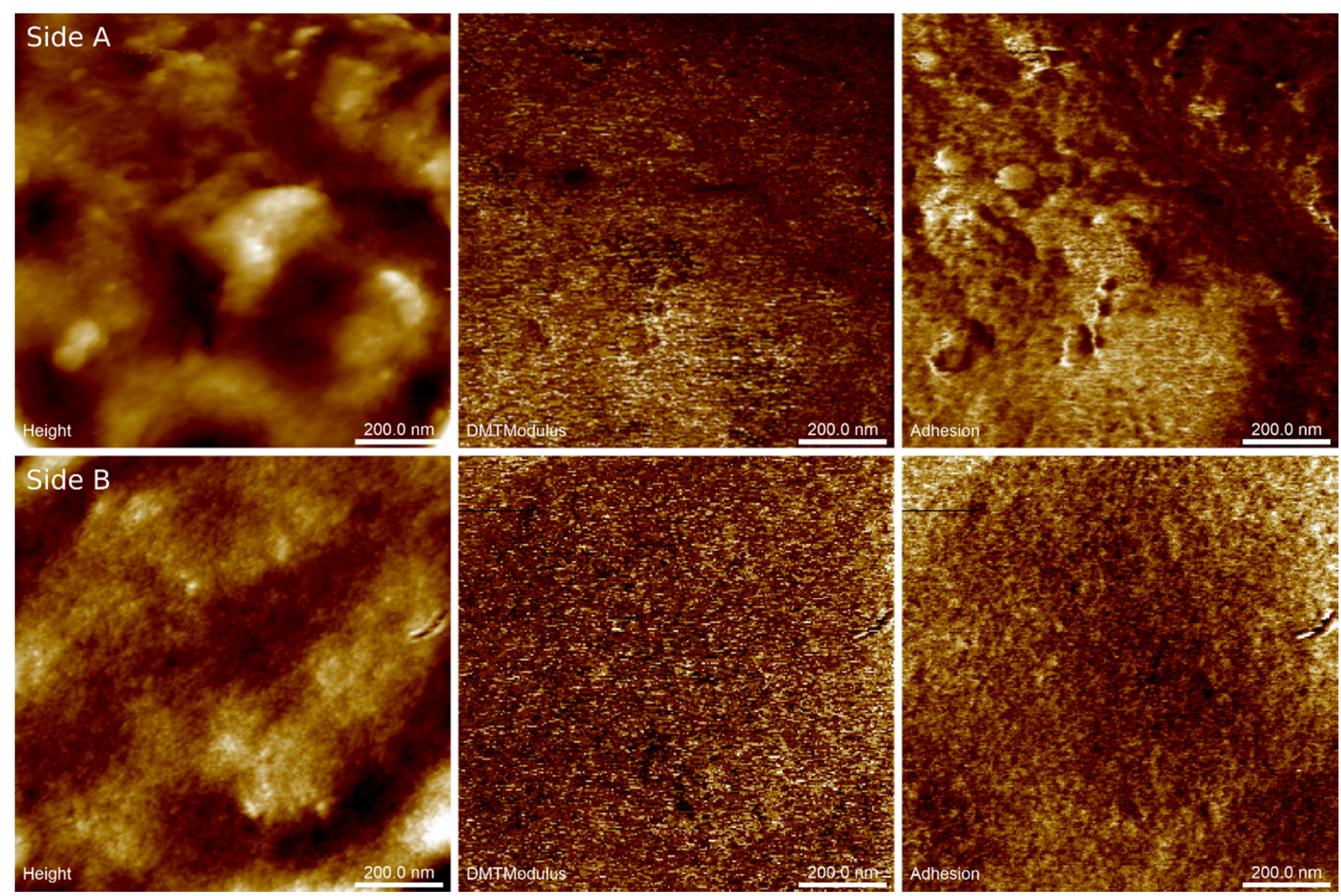

Figure 3. Example results of AFM nanomechanical mapping of both sides of the SGAK-I polymer foil: surface topography (Height), pseudo-Young's modulus (DMTModulus), tip-surface adhesion force (Adhesion). Scan area is $1 \times 1 \mu \mathrm{m}^{2}$. Side (A) internal structure of foil; Side (B) external structure of foil.

Basically, elastic properties of the materials are derived on the fly from the forcedisplacement curves recorded when the periodically modulated probe interacts with the sample surface. Initially, the retract curve is fitted using the Derjaguin-Muller-Toporov (DMT) model [28] to obtain the reduced Young's modulus. Subsequently, this parameter is converted into Young's modulus providing that the Poisson's ratio is known. Unfortunately, the sample Poisson's ratio is not generally accurately known, hence we refer to the obtained elastic modulus as the pseudo-modulus. Notwithstanding, the maps of this modulus demonstrate the structural homogeneity and phase purity of the material.

Imaging of the adhesion forces reveals subtle differences in tip-surface interactions that reflect variations in the thickness of the capillary layer on the surfaces. At several places on side A (ca. $100 \mathrm{~nm}$ in diameter), adhesion forces are substantially increased with respect to the remaining area. Note, however, that they are not spatially correlated with any visible structures in the height image. In contrast, distributions of pseudo-Young's modulus and adhesion forces on side B of the foil were found to be almost uniform, revealing structural and phase homogeneity.

Table 3 provides the averaged parameters of the topographical and mechanical complexity of the surfaces derived from AFM images of the tested films. Here, the parameters related to surface geometry (surface roughness $S_{\mathrm{q}}$, autocorrelation length $\mathrm{S}_{\mathrm{al}}$, and anisotropy ratio $S_{\text {tr }}$ ) are derived from autocorrelation or probability distribution functions, and therefore they ambiguously discriminate between various surface patterns. Notwithstanding these limitations, the performed calculations yielded results scattered enough to demonstrate the dissimilarity of the spatial characteristics of amplitude and surface patterns on both sides of each foil.

Inconclusive dependencies between the tested features of films presented in Table 3 may be the results of inhomogeneity of mixed raw materials with functional additives 
before film blowing because the blends were prepared at laboratory conditions, not at an industrial scale.

Table 3. Results of complex nanoscale mapping of both sides of biopolymer films obtained at $50 \mathrm{rpm}$ of the film-blowing laboratory line.

\begin{tabular}{|c|c|c|c|c|c|c|}
\hline $\begin{array}{l}\text { Sample/Rpm of } \\
\text { Film-Blowing } \\
\text { Laboratory Line }\end{array}$ & Film Side & $S_{\mathrm{q}}[\mathrm{nm}]$ & $\mathrm{S}_{\mathrm{al}}[\mathrm{nm}]$ & $S_{t r}$ & $\mathrm{Y}[\mathrm{MPa}]$ & $\mathbf{F}_{\mathrm{adh}}[\mathrm{nN}]$ \\
\hline \multirow{2}{*}{ SGA II/50 } & A & 3.71 & 96.1 & 0.796 & 444 & 1.82 \\
\hline & B & 2.82 & 77.2 & 0.755 & 266 & 2.73 \\
\hline \multirow{2}{*}{ SGA III/50 } & $\mathrm{A}$ & 6.25 & 72.1 & 0.398 & 564 & 2.43 \\
\hline & B & 5.44 & 82.7 & 0.298 & 298 & 2.19 \\
\hline \multirow{2}{*}{ SGAK I/50 } & $\mathrm{A}$ & 2.48 & 68.5 & 0.132 & 134 & 0.967 \\
\hline & B & 1.84 & 78.4 & 0.505 & 165 & 0.809 \\
\hline \multirow{2}{*}{ SGAK II/50 } & A & 3.67 & 93.2 & 0.866 & 925 & 2.06 \\
\hline & B & 2.08 & 74.9 & 0.364 & 333 & 1.07 \\
\hline \multirow{2}{*}{ SGAK III/50 } & A & 1.36 & 77.0 & 0.697 & 347 & 1.63 \\
\hline & B & 1.18 & 43.1 & 0.656 & 318 & 1.69 \\
\hline
\end{tabular}

A: internal surface, B: external surface, $\mathrm{S}_{\mathrm{q}}$ : surface roughness (RMS), $\mathrm{S}_{\mathrm{al}}$ : fastest lateral autocorrelation decay, $\mathrm{S}_{\mathrm{tr}}$ : surface texture anisotropy ratio, $\mathrm{Y}$ : surface-averaged Young's pseudo-modulus, $\mathrm{F}_{\mathrm{adh}}$ : surface-averaged tip-surface adhesion force.

As a rule, surfaces on side A appear rougher than those on side B according to the roughness parameter $\mathrm{S}_{\mathrm{q}}$ (mean value $3.5 \mathrm{~nm}$ ). This effect corresponds to the greater amplitude of large-scale surface patterns. In contrast, surfaces on side B are flatter (mean $\mathrm{S}_{\mathrm{q}}$ is $2.7 \mathrm{~nm}$ ), which is mainly due to the lesser height variations of nanosized features and a complete lack of larger structures. The surface roughness was found to be slightly larger in SGA samples than in SGAK ( $4.6 \mathrm{~nm}$ vs. $2.1 \mathrm{~nm}$, respectively) and this outcome demonstrates the flattening effect of keratin addition into the liquid mixture. Keratin might reduce the surface roughness in two ways: by increasing the surface tension in the fluid and/or by decreasing the heat flux transmitted outward, which subsequently slows down the cooling of the polymer.

According to the data listed in Table 3, there is straight dependence between surface roughness and specific autocorrelation decay $S_{a 1}$. The latter parameter defines arbitrarily the lower limit for the lateral size of predominant surface structures, which is found to be $81 \mathrm{~nm}$ vs. $71 \mathrm{~nm}$ for sides A and B, respectively. Straight correspondence between the horizontal and vertical sizes of the surface patterns demonstrates their rather uniform three-dimensional scaling.

Similar observations can be made concerning the texture anisotropy ratio $S_{t r}$, which increases with increasing surface roughness and autocorrelation length. On one hand, $S_{\operatorname{tr}}$ is a measure of the sensitivity of the surface patterns to the observation angle, but on the other, the inverse of $S_{\text {tr }}$ provides the magnification factor for the horizontal size of the dominant surface patterns. Hence, the increasing fraction of large-scale surface patterns on side A corresponds to more isotropic, though rough, surfaces; whereas the increasing amount of nanosized features on side $B$ results in pronounced directional alignments of structural components, that is, the surface layer.

The obtained results of nanomechanical mapping generally agree with previous conclusions drawn from height images. Larger values of Young's pseudo-modulus are found on sides A than B. This leads to the conclusion that elastic properties are determined by the relative content of surface components of various scale lengths. Similar to hardening, faster cooling results in the increasing contribution of large-scale patterns and a stiffer surface, whereas slower cooling leaves a nano-rough, though softer, surface. Likewise, 
adhesion forces are found to be larger on surfaces with greater roughness. Such an effect is likely due to the retention ability of the polymer to accumulate the capillary layer within the deepest parts of the surface. Here, the addition of keratin lowers the tip-surface interaction through the reduction of the surface roughness (thinner capillary layer) that was discussed in previous paragraphs.

\subsection{Results and Discussion of FTIR Spectroscopy}

ATR and FTIR are very popular techniques employed for elementary analysis of various types of organic compounds and materials containing, for instance, biodegradable components. These materials include, for example, thermoplastic starch, potato starch, technical glycerol, polyvinyl alcohol (PVA), polylactide (PLA), as well as keratin hydrolyzate, and many others. FTIR is also a useful tool for determining the content of the above compounds in various types of products where content significantly affects functionality. The application of FTIR to establish the content of the compounds in materials exhibiting biodegradable properties is confirmed by the increasing number of cases, including ours, reported in the literature on the subject $[27,29]$. The usefulness of FTIR for the study of this type of samples is mainly due to the fact that the absorption of moieties, such as the carbonyl group bands, especially that occurring during the intensification of the degradation effects in tested materials, or the content of additives used in the starch fraction of a tested product, increases relatively along with their growing volume. It should also be underlined that starch itself reveals very intense and interesting IR bands as it contains carbohydrates and plant polysaccharides. It consists mainly of glucose units linked by $\alpha$ -glycosidic bonds. There are two main fractions: first, unbranched amylose, which is made up of glucose residues linked together by oxygen atoms by $\alpha-1,4$-glycosidic bonds. The other component is branched amylopectin with additional $\alpha-1,6$-glycosidic bonds. The incorporation of the above-listed additives, which produce intense IR bands, also suggests a significant modification of molecular interactions in the obtained group of biodegradable film materials. These facts translate into evident changes in the FTIR spectra of the film selected for the study $[27,30]$.

For a more convenient analysis of the obtained FTIR spectra, the relevant panels in Figures 4 and 5 demonstrate and Table 4 lists all more significant vibrations, together with their assignment to specific functional groups, based on the available literature [27,31-35]. It is clearly visible that there were noticeable changes to the structure of the tested films after using the selected additives. The changes are also discernible at the molecular level in the form of changes in the IR spectra. This is attributable both to the amount of the additive used and the rotational speed of the extruder device [27,36]. Evidently, all the tested samples contain a low content of water molecules. This confirms the presence of moderately intense bands in the region around $1660 \mathrm{~cm}^{-1}$, which should be rated as deformation vibrations - $\mathrm{OH}$, and vibrations in the range of $3550-3100 \mathrm{~cm}^{-1}$ with an intense peak at $\sim 3300 \mathrm{~cm}^{-1}$. These, in turn, are derived from the stretching vibrations of $-\mathrm{OH}$ groups. Both of these vibration regions are also likely to originate from the molecules of the main constituent component of these materials, that is, starch, which contains a significant number of $-\mathrm{OH}$ groups. In addition, the additives used also contain $-\mathrm{OH}$ groups. The vibrations in the region of $3500-3100 \mathrm{~cm}^{-1}$, that is, stretching vibrations of the -OH groups, can also be strengthened by free, internal, and external molecular hydrogen bonds occurring in the starch structure [32,34]. These become particularly active upon the incorporation of the additives that also contain them, and, as the percentage share of selected additives increases, hydrogen bonds may form between them and starch molecules. The bonds modify the starch internal structure and thus alter vibration intensity. It is worth noting that the vibrations from the peak of $\sim 1660 \mathrm{~cm}^{-1}$, or deformation $-\mathrm{OH}$, can also be strengthened by the vibrations of the water molecules contained within the starch. Another noteworthy vibration range is 3000-2700. These are indicative of the symmetric and asymmetric $\mathrm{C}-\mathrm{H}$ stretching vibrations in $-\mathrm{CH}_{2}$ groups [29]. Moreover, the vibration area from 1200 to $1000 \mathrm{~cm}^{-1}$ seems to be relevant as well, with its $\mathrm{C}-\mathrm{O}$ stretching vibrations. 
This area exhibits vibrations originating from the $\mathrm{C}-\mathrm{O}-\mathrm{C}$ group naturally occurring in polysaccharides. In contrast, the area from 930 and below down to about $700 \mathrm{~cm}^{-1}$ is characteristic of vibrations of the polysaccharide ring, while vibrations falling under this can be ascribed to the pyranose ring in individual units belonging to a single glucose unit.

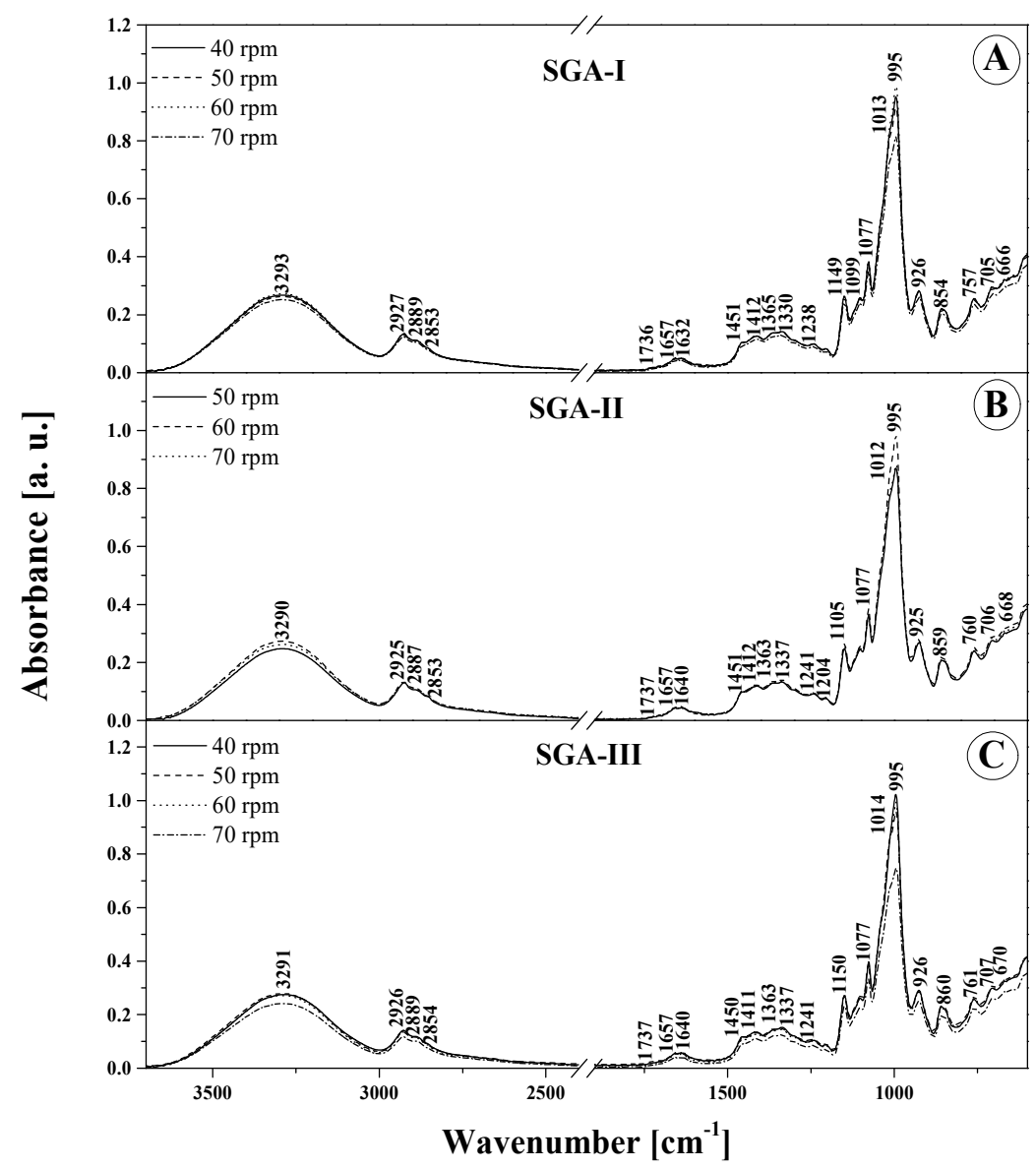

Figure 4. ATR-FTIR absorption spectra for the analyzed films: SGA-I (A) and SGA-II (B) and SGAIII (C). Numbers next to peaks are the wavenumbers for each component. Different lines indicate various screw speeds (rpm) during film blowing processing.

In the wavenumber range $3550-3100 \mathrm{~cm}^{-1}$ (Figures 4 and 5 and Table 4 ), the characteristic broad band that corresponds to the stretching vibrations of the $-\mathrm{OH}$ group displays the highest intensity for both types of SGA and SGAK films for the smallest amounts of additives used and, above all, for the lowest rotational speed values of the extruding device. In these cases, the peak of this spectrum is also slightly shifted towards higher wavenumbers, which implies the formation of more intermolecular hydrogen bonds with water molecules in the samples. This is further evidenced by the greater intensity of the spectrum associated with deformational vibrations of $-\mathrm{OH}$ groups at $\sim 1640 \mathrm{~cm}^{-1}$, which is associated with vibrations in starch itself. Regarding vibrations in the range of $3100-2700 \mathrm{~cm}^{-1}$, typical of $-\mathrm{CH}_{2}$ stretching vibrations, the most intense spectra are seen in films with the lowest volumes of additives, especially keratin. This may be attributed to the higher content of amylose and amylopectin, as well as a much greater strength of intermolecular forces in the studied additives than that in alcohol. Moreover, in the FTIR spectra of films modified with all the tested additives, very profound changes were also observed in bands with a peak at around 1240-80 and 940-1200 $\mathrm{cm}^{-1}$. These vibrations are related to the skeletal vibrations of the $\mathrm{C}-\mathrm{O}$ and $\mathrm{C}-\mathrm{C}$ groups that typify starch and can be reinforced by vibrations originating in the additives [37]. Primarily, this testifies to a very good mixing of ingredients used in the production of film blends, meaning that they are 
relatively homogeneous. Secondly, it shows the existence of strong interactions between them, as strong hydrogen bonds between individual groups were established. Below about $870 \mathrm{~cm}^{-1}$, there are bands characteristic of $\alpha$-glycosidic bonds, that is, typical of starch. It is also worth highlighting that noticeable changes in this area occur mainly with the increase in the rotational speed of the extruder device. They evidence the structural changes within the glycosidic bond that connects the molecules.

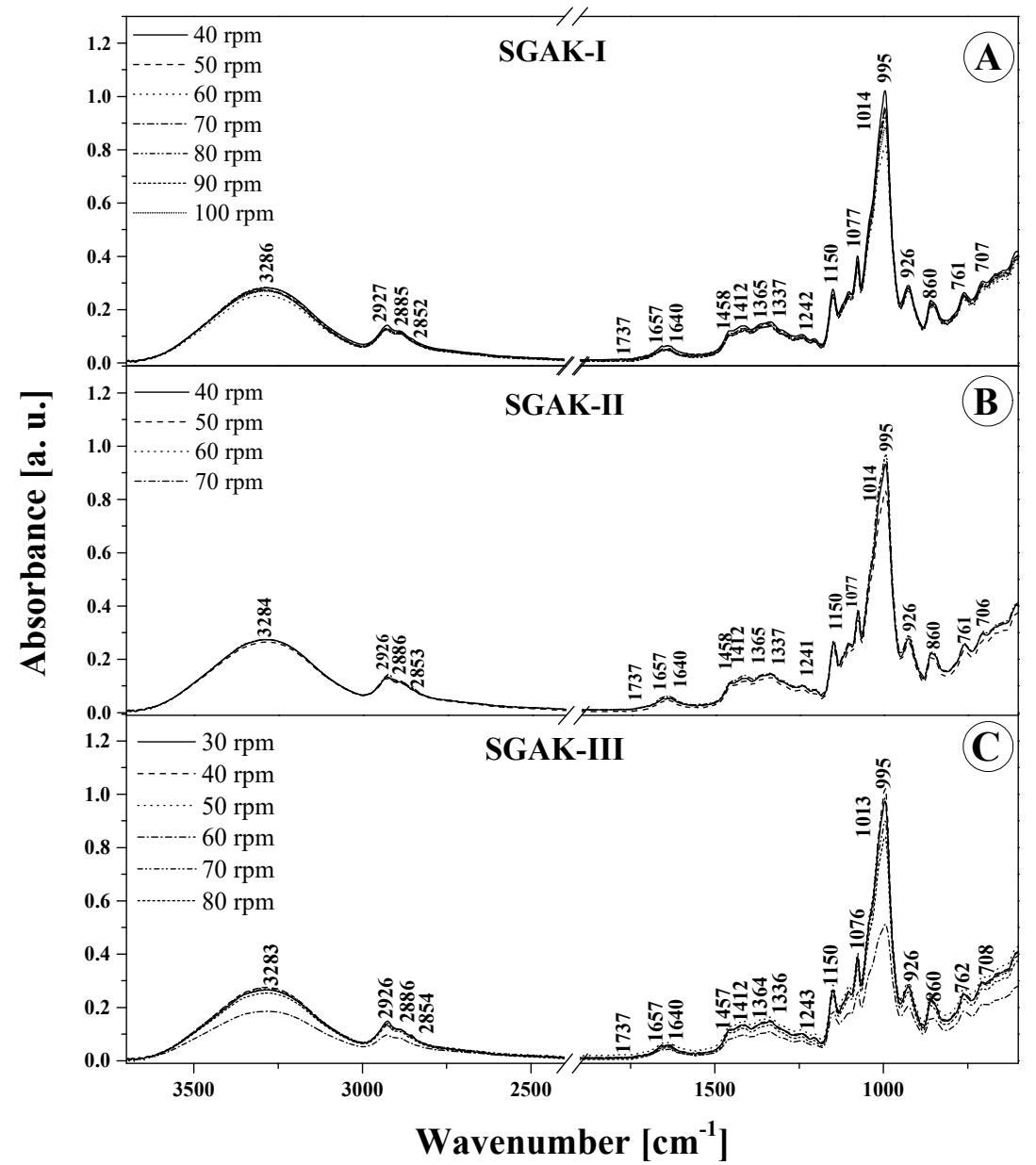

Figure 5. ATR-FTIR absorption spectra for the analyzed films: SGAK-I (A), SGAK-II (B), and SGAKIII (C). Numbers next to peaks are the wavenumbers for each component. Different lines indicate various screw speeds (rpm) during film blowing processing.

To sum up, it is worth noting that the tested additives modify the FTIR spectrum of the tested films in a noticeable, yet not profound manner. Both for SGA and SGAK films the infrared spectra of the tested materials are very similar over the entire range of additive volumes. This proves the relatively high quality and stability of the material [26]. For a more detailed comparison and in an attempt to identify significant differences in the samples, chemometric analysis was applied further in the work. 
Table 4. Location of the peaks of FTIR absorption bands, along with the assignment of relevant vibrations to the materials selected for testing biodegradable SGA and SGAK films over the spectral range from 3800 to $500 \mathrm{~cm}^{-1}$.

\begin{tabular}{|c|c|c|}
\hline \multicolumn{2}{|c|}{ Maximum Position $\left(\mathrm{cm}^{-1}\right)$} & \multirow{2}{*}{ Types and Origin of Vibrations } \\
\hline SGA & SGAK & \\
\hline 3290 & 3286 & $v(-\mathrm{OH})$ with absorber water or $\mathrm{O}-\mathrm{H} \ldots \mathrm{O}-\mathrm{H}$ \\
\hline 2929 & 2927 & $v_{\text {as }}(\mathrm{C}-\mathrm{H})$ \\
\hline 2878 & 2886 & $v_{\mathrm{s}}(\mathrm{C}-\mathrm{H})$ \\
\hline $\begin{array}{l}1657 \\
1634\end{array}$ & $\begin{array}{l}1657 \\
1640\end{array}$ & $\delta_{\mathrm{m}}(\mathrm{O}-\mathrm{H})(\mathrm{e} . \mathrm{g} .$, absorber water $)$ \\
\hline $\begin{array}{l}1451 \\
1365\end{array}$ & $\begin{array}{l}1557 \\
1365\end{array}$ & $\delta(\mathrm{C}-\mathrm{H})$ or $\delta\left(\mathrm{CH}_{2}\right)$ in plane \\
\hline 1412 & 1412 & $\mathrm{C}-\mathrm{H}$ bending and wagging or $\delta(\mathrm{COH})$ \\
\hline $\begin{array}{l}1149 \\
1077\end{array}$ & $\begin{array}{l}1150 \\
1077\end{array}$ & $\begin{array}{l}\text { anhydroglucose ring } \mathrm{C}-\mathrm{O} \text { stretch of } \mathrm{C}-\mathrm{O}-\mathrm{H} \text { in starch and } \\
\mathrm{C}-\mathrm{O}-\mathrm{C} \text { antisymmetric bridge }\end{array}$ \\
\hline $\begin{array}{c}1014 \\
995\end{array}$ & $\begin{array}{c}1014 \\
995\end{array}$ & $v(\mathrm{C}-\mathrm{O})$ and $v(\mathrm{C}-\mathrm{O}-\mathrm{C}$ or $\mathrm{C}-\mathrm{O}-\mathrm{H})$ \\
\hline $\begin{array}{l}926 \\
857 \\
761\end{array}$ & $\begin{array}{l}926 \\
860 \\
731\end{array}$ & $\begin{array}{c}v(\mathrm{C}-\mathrm{C}) \text { and } v(\mathrm{C}-\mathrm{O}) \text { or } \mathrm{C}-\mathrm{O}-\mathrm{C} \text { bend or } \mathrm{O}-\mathrm{H} \text { deformation } \\
\text { (broadened by water) }\end{array}$ \\
\hline
\end{tabular}

v-stretching, $\delta$-deformation, s-symmetrical, as-asymmetric, m-medium.

\section{Results of Multivariate Analysis}

In order to evaluate the main differences in the FTIR spectra of the biodegradable films, multivariate analysis was applied to two regions: $3700-600 \mathrm{~cm}^{-1}$ and $1800-600 \mathrm{~cm}^{-1}$. The contribution of the principal components is shown in Table 5. The most common features among samples are generally expressed by the first few principal components (PCs). A general criterion for determining the number of PCs is a graphical representation known as a scree plot. This is presented in Figure 6. A scree plot represents the graphic relationship between the eigenvalues in decreasing order against the corresponding PCs. The number of PCs can be determined by locating the point at which the graph shows stabilization in the slope. In our analysis, the first two principal components explain more than $96.67 \%$ and $87.09 \%$ of the total variance (structure of dependence of primary variables) for wavenumber ranges $1800-600 \mathrm{~cm}^{-1}$ and $3700-600 \mathrm{~cm}^{-1}$, respectively. Based on these results, for both spectral regions, the two main components underwent further study as they exhibit the strongest influence of total variance. The scores and loading plots for PC1 and PC2 for $1800-600 \mathrm{~cm}^{-1}$ region is shown in Figure 7. 
Table 5. Eigenvalues, percentage of variance, and cumulative percentage in the data used for the PCA.

\begin{tabular}{|c|c|c|c|}
\hline $\begin{array}{c}\text { Principal } \\
\text { Component Number }\end{array}$ & Eigenvalue & Percentage of Variance (\%) & Cumulative (\%) \\
\hline \multicolumn{4}{|l|}{$1800-600 \mathrm{~cm}^{-1}$} \\
\hline 1 & 1417.510 & 84.32540 & 84.32540 \\
\hline 2 & 207.643 & 12.35235 & 96.67775 \\
\hline 3 & 27.749 & 1.65077 & 98.32852 \\
\hline 4 & 10.786 & 0.64165 & 98.97016 \\
\hline 5 & 5.509 & 0.32773 & 99.29789 \\
\hline 6 & 3.852 & 0.22917 & 99.52706 \\
\hline 7 & 2.880 & 0.17132 & 99.69839 \\
\hline 8 & 1.848 & 0.10996 & 99.80835 \\
\hline 9 & 0.902 & 0.05368 & 99.86202 \\
\hline 10 & 0.630 & 0.03746 & 99.89948 \\
\hline \multicolumn{4}{|l|}{$3700-600 \mathrm{~cm}^{-1}$} \\
\hline 1 & 2888.032 & 66.52919 & 66.52919 \\
\hline 2 & 892.380 & 20.55702 & 87.08621 \\
\hline 3 & 255.357 & 5.88246 & 92.96866 \\
\hline 4 & 146.479 & 3.37431 & 96.34297 \\
\hline 5 & 68.177 & 1.57055 & 97.91352 \\
\hline 6 & 30.603 & 0.70497 & 98.61849 \\
\hline 7 & 14.455 & 0.33299 & 98.95148 \\
\hline 8 & 12.699 & 0.29253 & 99.24401 \\
\hline 9 & 7.811 & 0.17992 & 99.42394 \\
\hline 10 & 6.106 & 0.14066 & 99.56460 \\
\hline
\end{tabular}

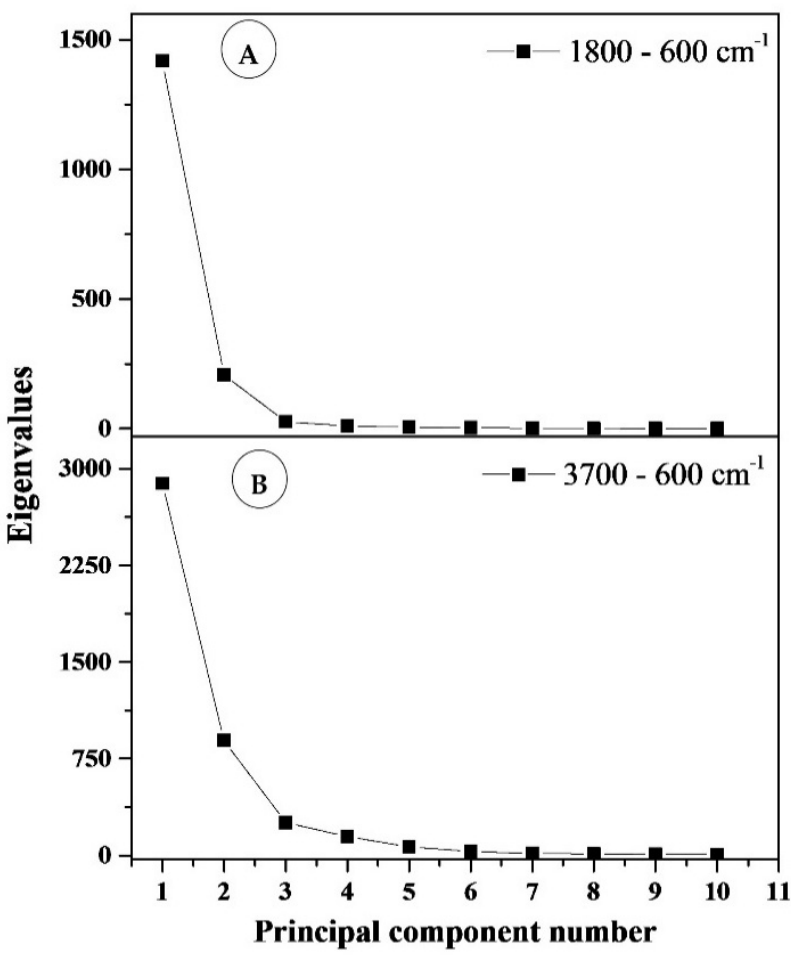

Figure 6. Scree plots (eigenvalues from principal components): (A) for the section $1800-600 \mathrm{~cm}^{-1}$, (B) for the section $3700-600 \mathrm{~cm}^{-1}$. 

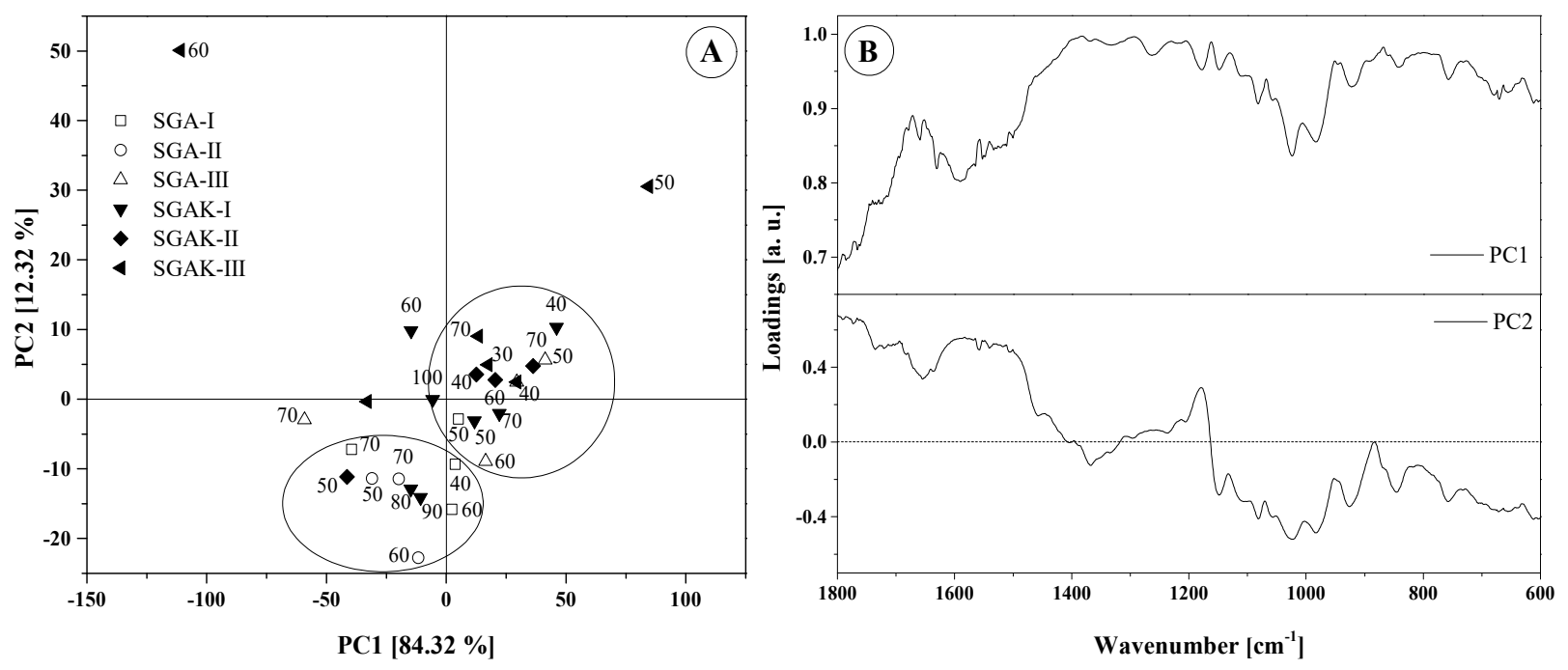

Figure 7. Results of PCA analysis: (A) Score plot (numbers on graph are rpm during film blowing); (B) Loadings plot for region $1800-600 \mathrm{~cm}^{-1}$.

\section{1. $1800-600 \mathrm{~cm}^{-1}$}

For the fingerprint region, the two principal components compel the placement of samples into two main groups. However, some samples could not be grouped. SGAK-III processed at $50 \mathrm{rpm}$ and SGAK-III processed at $60 \mathrm{rpm}$ during film blowing are separated, as according to Figure 5, the intensity of spectra for these samples differs from the others. This effect could affect the result of the analysis. In the case of SGA groups, which differ in potato starch and polyvinyl alcohol content, PCA analysis also displayed a difference between these groups. SGA-II are negatively correlated with PC1, while SGA-III are mainly positively correlated with PC1, and SGA-I is located in the middle of the graph. Moreover, samples from SGAK-I, SGAK-II, and SGAK-II show similarity between groups and it is more difficult to separate them.

It can be observed that the extrusion process and the extruder screw speed are factors determining the division and clustering into groups. Furthermore, all samples obtained at $40 \mathrm{rpm}$ of film-blowing laboratory line are located in the same cluster.

The type of addition also has a significant impact on the classification of the biodegradable film. The use of polyvinyl alcohol allows the division of the studied samples depending on the amount of employed additive. In the case of simultaneous use of polyvinyl alcohol and keratin, the division of samples into clusters is much more complicated. In Figure 7B, the loading plot reveals the wavenumbers that explain the distinction of samples. The PC1 loading shows that samples that are positively correlated with PC1 in the score plot are characterized by spanning the entire range $\left(1800-600 \mathrm{~cm}^{-1}\right)$. The arrangement of points on the PC1 vs. PC2 graph, however, is related to the differences in intensities for the range $1460-760 \mathrm{~cm}^{-1}$. The greatest diversity occurs at $\sim 1015 \mathrm{~cm}^{-1}$ and $\sim 995 \mathrm{~cm}^{-1}$, which is connected with stretching vibrations $(\mathrm{C}-\mathrm{O})$ and $(\mathrm{C}-\mathrm{O}-\mathrm{C}$ or $\mathrm{C}-\mathrm{O}-\mathrm{H})$.

Figure 8 presents the three diagrams obtained from the hierarchical clustering analysis using the FTIR spectra from the fingerprint region. The application of Ward method linkage and Pearson correlation distance as HCA criteria gives us similar results to that of PCA analysis. The results were divided into four clusters in order to better visualize the data. Here, SGAK-III-60 rpm shows no similarity to other samples. 


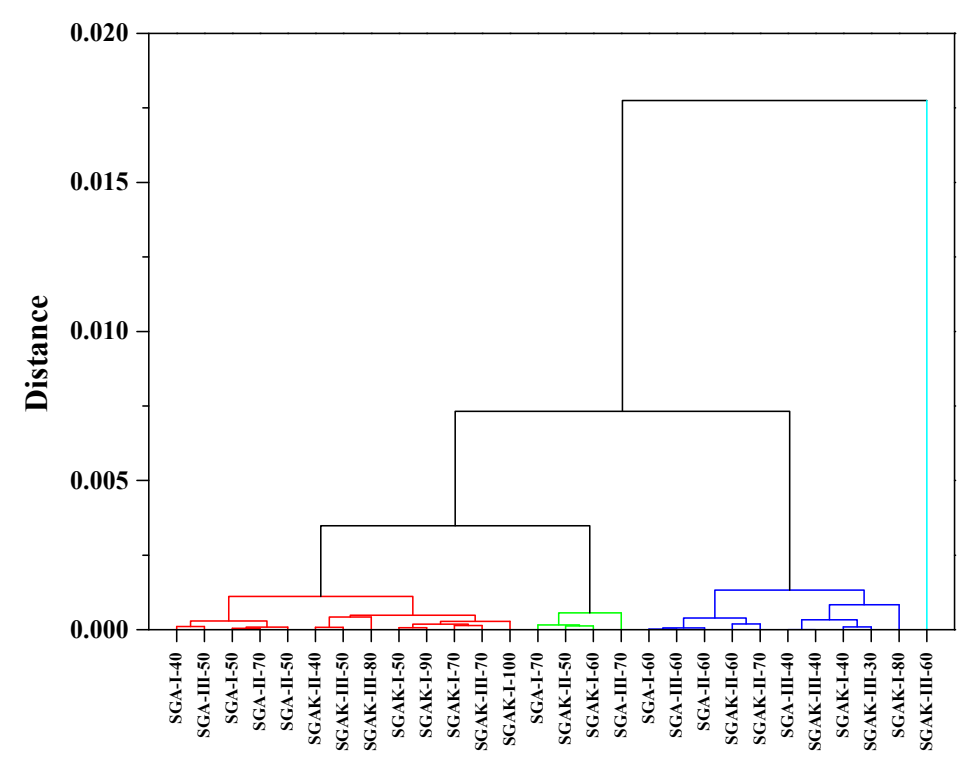

Figure 8. HCA analysis for region $1800-600 \mathrm{~cm}^{-1}$. Linkage criteria-Ward method. Clustering metric-Pearson correlation. Different colors indicate similarity clusters.

\section{2. $3700-600 \mathrm{~cm}^{-1}$}

PCA obtained for the $3700-600 \mathrm{~cm}^{-1}$ range reveals that the FTIR spectra fell into two different groups, similar to that of the fingerprint region (Figure 9A). Sample SGAK-III processed at $50 \mathrm{rpm}$ and SGAK-III processed at $60 \mathrm{rpm}$ during film blowing are clearly separated from each other. Most samples are, naturally, focused on the center of the graph. Samples from SGA-I and SGA-II are negatively correlated with PC2, whereas SGA-III are positively correlated with PC1. It can be assumed that the contents of potato starch and polyvinyl alcohol have a greater impact on the division of samples rather than the extruder screw speed.
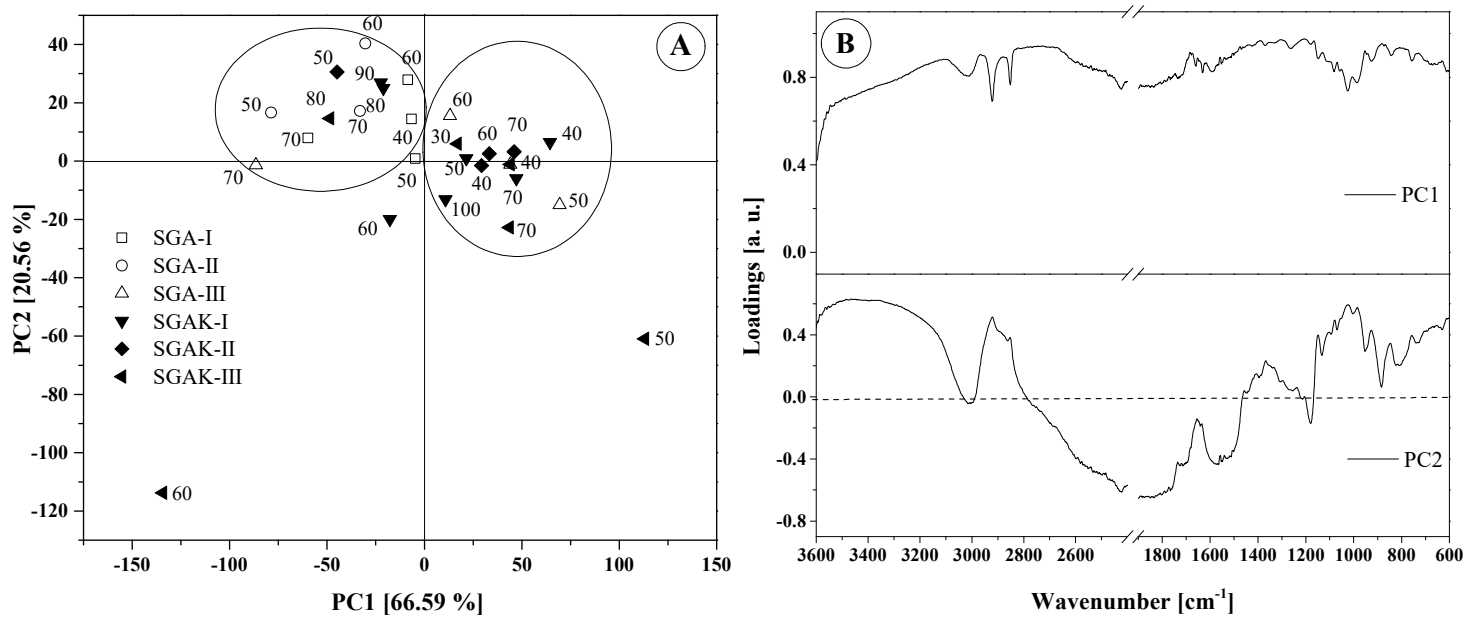

Figure 9. Results of PCA analysis: (A) Score plot (numbers on graph are rpm during film blowing); (B) Loadings plot for region $3700-600 \mathrm{~cm}^{-1}$.

The loading plot presented in Figure 9B confirms the significant influence of the entire spectral range between $3500-600 \mathrm{~cm}^{-1}$ on the arrangements of points in the score plot. From the given range, it follows that samples with the addition of polyvinyl alcohol and polyvinyl alcohol with keratin show significant similarity. In the dendrogram of Figure 10, using average linkage and Pearson correlation as distance measures, we obtain two main clusters. In one, the cluster is more diverse and at 0.001 units of distance can be divided into three clusters, similar to PCA in Figure 9A. Samples SGAK-III processed at $50 \mathrm{rpm}$ and 
SGAK-III processed at $60 \mathrm{rpm}$ during film blowing showed no similarity to other samples.

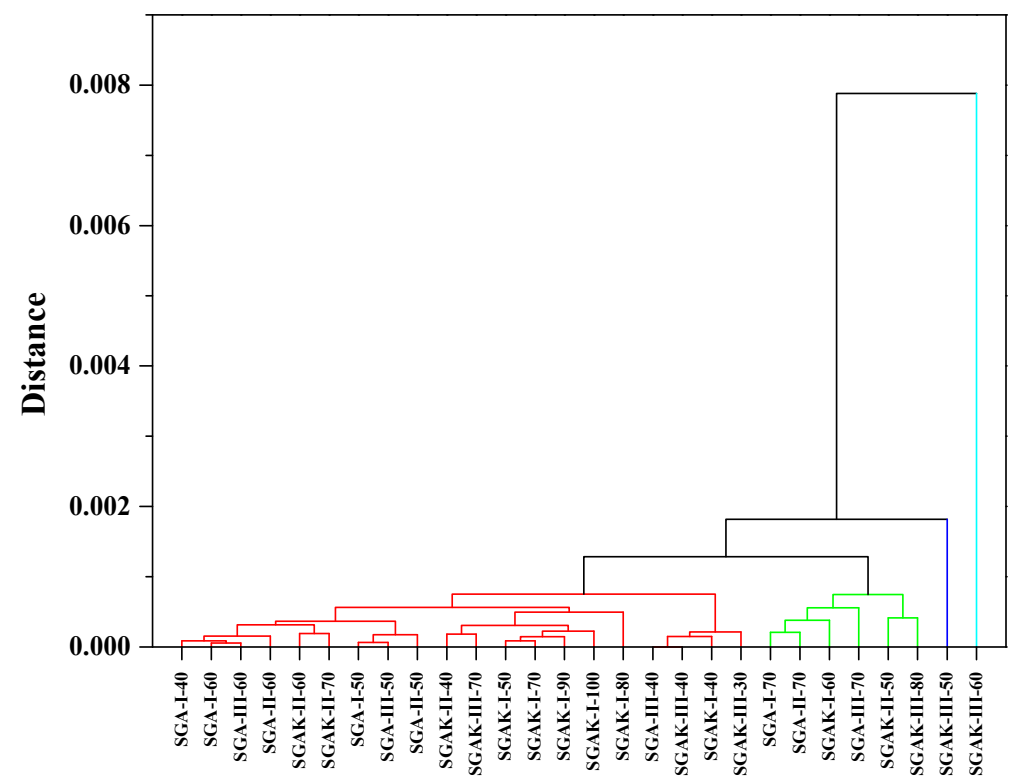

Figure 10. HCA analysis for region $3700-600 \mathrm{~cm}^{-1}$. Linkage criteria-average linkage. Clustering metric-Pearson correlation. Different colors indicate similarity clusters.

In Figures 4 and 5, which present the ATR-FTIR absorption spectra of the produced biodegradable films, and Table 4, which lists the position of the maxima of FTIR absorption spectra, it can be observed that there are small differences in the band shifting. This may be the effect of multivariate analysis. The most significant differences are in the intensity of bands between samples and are due to differences in extruder screw speed.

\subsection{XRD Results}

Figure 11 presents a typical diffractogram of the investigated polymers. The crystalline phase is characterized by three relatively strong reflections (intensity above 7) at theta of $17.2^{\circ}, 20.1^{\circ}$, and $22.6^{\circ}$, and three weak ones (intensity $3-4$ ) at $30.5^{\circ}, 34.6^{\circ}$, and $38.8^{\circ}$. Based on data from Table 6 , the average degree of crystallinity for every group of compounds is: SGAK-I 0.378, SGAK-II 0.339, SGAK-III 0.379, SGA-I 0.413, and SGA-III 0.398. The results suggest that the addition of the keratin slightly lowers the content of the crystalline phase. However, the effect of polyvinyl alcohol on the degree of crystallinity is not observed in the investigated range. The amount of crystalline phase also cannot be correlated with the speed of the extruder rotation. This effect can be related to the inhomogeneity of the measured samples, which can be caused by, for example, the different cooling rates of the foil fragments.

Table 6. Degree of crystallinity of measured samples.

\begin{tabular}{cc}
\hline Sample/Rpm of Film-Blowing Laboratory Line & Degree of Crystallinity \\
\hline SGAK-I/50 & 0.375 \\
SGAK-I/60 & 0.381 \\
SGAK-II/50 & 0.349 \\
SGAK-II/60 & 0.330 \\
SGAK-III/50 & 0.377 \\
SGAK-III/60 & 0.381 \\
SGA-II/50 & 0.452 \\
SGA-II/60 & 0.375 \\
SGA-III/50 & 0.386 \\
SGA-III/60 & 0.410 \\
\hline
\end{tabular}




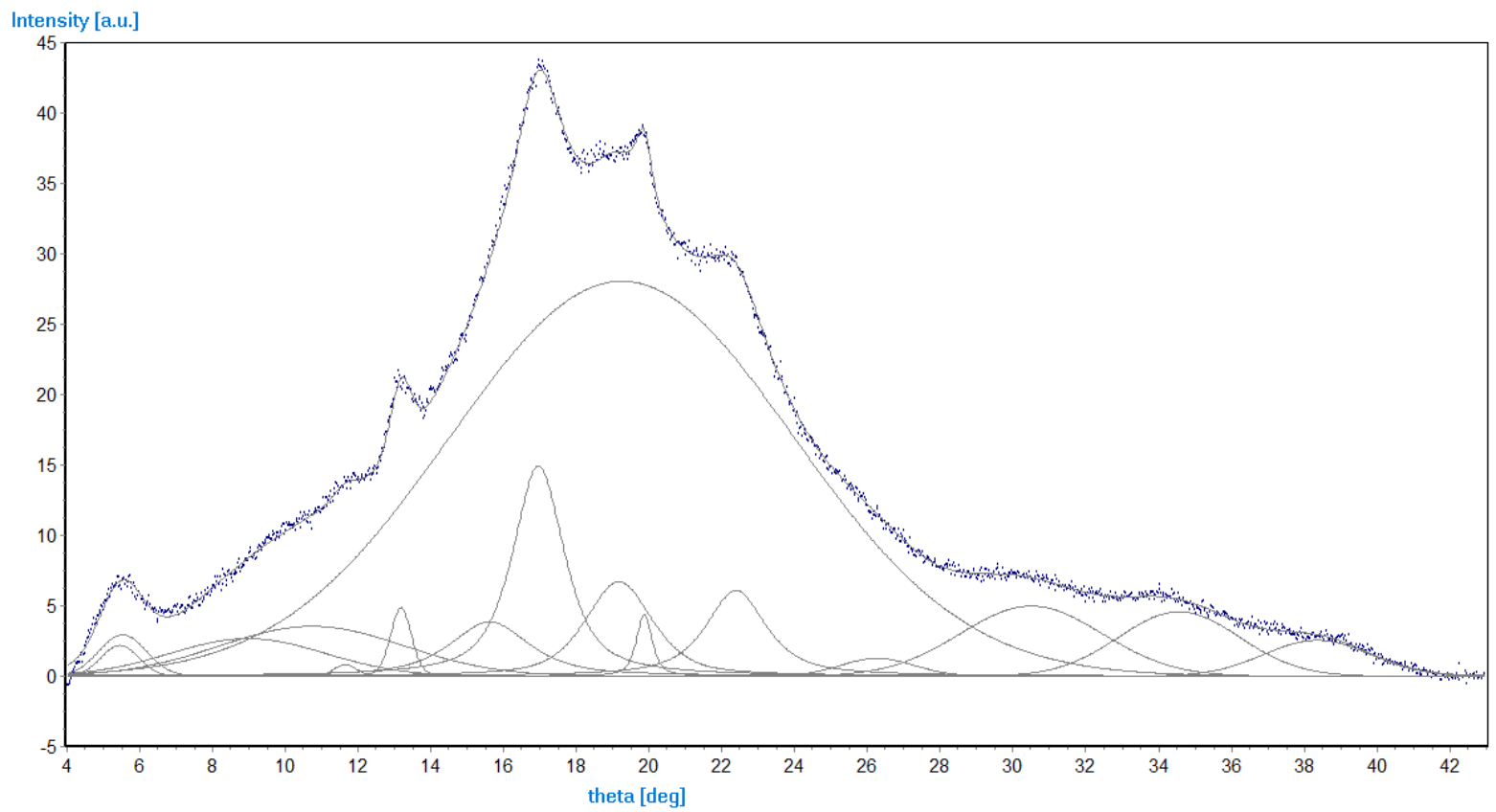

Figure 11. Experimental points (blue) of SGAK-I/50 rpm and model curves (grey). The curve with FWHM (full width at half maximum) of $11^{\circ}$ describes the amorphous phase.

\section{Conclusions}

Increase in the extrusion-cooking efficiency was observed upon increase in polyvinyl alcohol and keratin content. Higher values were also obtained for samples containing the two functional additives. In addition, an increase in the amount of polyvinyl alcohol and keratin, results in a lower extrusion-cooking process SME. Furthermore, lower energy consumption values of extrusion-cooking were noted for samples containing both functional additives. It is worth noting that with these processed raw material mixtures, the process was extremely stable and smooth, which is also evidenced by load tests of the plasticizing system in relation to the extruder drive.

Nanoscale studies by means of AFM method application reveal significant differences in biopolymer foil topographical and mechanical characteristics with regard to both sides of the same sample and to the possible effect of keratin. The differences between opposites sides of the same sample are caused by variations in the heat flux through foil/air and foil/holder interface thermal barriers that determine the cooling rate of the melt. In contrast, the effect of keratin is demonstrated in reduction in adhesion forces via the flattening of the sample surface, which might be indirectly related to the changes in specific thermal properties of the material, such as specific heat, softening temperature etc. This is evidenced in that AFM imaging reveals large structural inhomogeneities in cross-sectional views of the biopolymers.

The X-ray diffraction studies also confirm the effect of keratin on tested materials. In this case, the addition of this component lowers the degree of crystallinity, which may reduce the brittleness of the investigated materials. At the same time, no effect of polyvinyl alcohol addition was observed in the investigated range.

The research conducted with the FTIR technique made it possible to assess the effect of the additives on intermolecular interactions in qualitative terms. The research also confirmed the homogeneity of obtained samples, both for SGA and SGAK films, during the preparation of raw material mixtures.

Author Contributions: Conceptualization, M.C., T.O., K.K., A.W., M.M. (Marek Milanowski) and M.G.; Data curation, M.C., T.O., K.K., A.W., M.M. (Marek Milanowski), I.B-W., D.K. (Dariusz Karcz), D.K. (Daniel Kaminski), S.K., M.G., I.K., L.Ś. and A.M.; Formal analysis, M.C., A.W., I.B-W., D.K. (Dariusz Karcz), D.K. (Daniel Kaminski), S.K. and A.M.; Funding acquisition, M.C. and T.O.; In- 
vestigation, M.C., T.O., K.K., M.M. (Marek Milanowski), J.S., D.K. (Dariusz Karcz), D.K. (DANIEL KAMINSKI), S.K., M.G. and L.Ś.; Methodology, M.C., K.K., A.W., M.M. (Marcin Mitrus), J.S., I.B.-W., D.K. (Daniel Kaminski), S.K., K.W.-K., K.K.-D., I.K. and A.M.; Project administration, M.C. and A.M.; Resources, T.O., K.K., M.M. (Marcin Mitrus), J.S., K.W.-K., K.K.-D. and I.K.; Software, I.B.-W., L.Ś. and A.M.; Supervision, M.C., A.W. and M.M. (Marcin Mitrus); Validation, M.C.; Writing—original draft, M.C., T.O., I.B.-W., K.W.-K., K.K.-D. and A.M. All authors have read and agreed to the published version of the manuscript.

Funding: Partly funded from the 'Excellent science' program of the Ministry of Education and Science as a part of the contract no. DNK/SP/465641/2020 "The role of the agricultural engineering and environmental engineering in the sustainable agriculture development".

Institutional Review Board Statement: Not applicable.

Informed Consent Statement: Not applicable.

Data Availability Statement: The data presented in this study are available on request from the corresponding authors.

Conflicts of Interest: The authors declare no conflict of interest. The funders had no role in the design of the study; in the collection, analyses, or interpretation of data; in the writing of the manuscript, or in the decision to publish the results.

\section{References}

1. Shen, L.; Haufe, J.; Patel, M.K. Product Overview and Market Projection of Emerging Bio-Based Plastics PRO-BIP 2009; Report for European polysaccharide network of excellence (EPNOE) and European bioplastics; Universiteit Utrecht: Utrecht, The Netherlands, 2009; p. 243.

2. Geyer, R.; Jambeck, J.R.; Law, K.L. Production, use, and fate of all plastics ever made. Sci. Adv. 2017, 3, e1700782. [CrossRef]

3. Platt, D.K. Biodegradable Polymers: Market Report; iSmithers Rapra Publishing: Shropshire, UK, 2006.

4. Jamróz, E.; Para, A. Folie biopolimerowe-alternatywa dla folii sztucznych. Aura 2017, 04, 14-15.

5. Siwek, P.; Libik, A.; Domagała-Świątkiewicz, I.; Kalisz, A.; Krucińska, I.; Puchalski, M.; Ciechańska, D.; Sulak, K. Biodegradowalne materiały włókniste dla rolnictwa. Aura 2019, 9, 11-13.

6. Menzel, C.; Gonzales-Martinez, C.; Chiralt, A.; Vilaplana, F. Antioxidant starchfilms containing sunflower hull extracts. Carbohydr. Polym. 2019, 214, 142-151. [CrossRef]

7. Lauer, M.K.; Smith, R.C. Recent advances in starch-based films toward food packaging applications: Physicochemical, mechanical, and functional properties. Compr. Rev. Food Sci. Food Saf. 2020, 19, 3031-3083. [CrossRef] [PubMed]

8. Yang, Z.; Graiver, D.; Narayan, R. Extrusion of Humidity-Resistant Starch Foam Sheets. Polym. Eng. Sci. 2012, 53, 857-867. [CrossRef]

9. Vladescu, A.; Vranceanu, D.M.; Kulesza, S.; Ivanov, A.N.; Bramowicz, M.; Fedonnikov, A.S.; Braic, M.; Norkin, I.A.; Koptyug, A.; Kurtukova, M.O. Influence of the electrolyte's $\mathrm{pH}$ on the properties of electrochemically deposited hydroxyapatite coating on additively manufactured Ti64 alloy. Sci. Rep. 2017, 7, 1-20. [CrossRef]

10. Solaymani, S.; Kulesza, S.; Țălu, Ş.; Bramowicz, M.; Nezafat, N.B.; Dalouji, V.; Rezaee, S.; Karami, H.; Malekzadeh, M.; Dorbidi, E.S. The effect of different laser irradiation on rugometric and microtopographic features in zirconia ceramics: Study of surface statistical metrics. J. Alloy. Compd. 2018, 765, 180-185. [CrossRef]

11. Kulesza, S.; Bramowicz, M.; Czaja, P.; Jabłoński, R.; Kropiwnicki, J.; Charkiewicz, M. Application of Atomic Force Microscopy for Studies of Fractal and Functional Properties of Biomaterials. Acta Phys. Pol. A 2016, 130, 1013-1015. [CrossRef]

12. Ţălu, Ş.; Bramowicz, M.; Kulesza, S.; Fiorillo, I.; Giovanzana, S. Fractal features and surface micromorphology of unworn surfaces of rigid gas permeable contact lenses. Curr. Eye Res. 2017, 42, 1118-1123. [CrossRef] [PubMed]

13. Vranceanu, D.; Cotrut, C.; Bramowicz, M.; Titorencu, I.; Kulesza, S.; Kiss, A.; Berbecaru, A.; Pruna, V.; Branzei, M.; Vladescu, A. Osseointegration of sputtered SiC-added hydroxyapatite for orthopaedic applications. Ceram. Int. 2016, 42, 10085-10093. [CrossRef]

14. Vladescu, A.; Cotrut, C.M.; Azem, F.A.; Bramowicz, M.; Pana, I.; Braic, V.; Birlik, I.; Kiss, A.; Braic, M.; Abdulgader, R. Sputtered $\mathrm{Si}$ and Mg doped hydroxyapatite for biomedical applications. Biomed. Mater. 2018, 13, 025011. [CrossRef] [PubMed]

15. Goździejewska, A.M.; Gwoździk, M.; Kulesza, S.; Bramowicz, M.; Koszałka, J. Effects of suspended micro-and nanoscale particles on zooplankton functional diversity of drainage system reservoirs at an open-pit mine. Sci. Rep. 2019, 9, 1-13. [CrossRef]

16. Rydzkowski, T.; Kulesza, S.; Bramowicz, M.; Michalska-Pożoga, I. Atomic force microscopy with fractal studies of temperature induced changes in the surface topography of polymeric materials. Polimery 2020, 65, 25-32. [CrossRef]

17. Matysiak, A.; Wójtowicz, A.; Oniszczuk, T. Process efficiency and energy consumption during the extrusion of potato and multigrain formulations. Agric. Eng. 2018, 22, 49-57. [CrossRef]

18. Ryu, G.H.; $\mathrm{Ng}$, P.K.W. Effects of selected process parameters on expansion and mechanical properties of wheat flour and whole cornmeal extrudates. Starch-Starke 2001, 53, 147-154. [CrossRef] 
19. Samborska, K.; Wiktor, A.; Jedlińska, A.; Matwijczuk, A.; Jamróz, W.; Skwarczyńska-Maj, K.; Kiełczewski, D.; Tułodziecki, M.; Błażowski, Ł.; Witrowa-Rajchert, D. Development and characterization of physical properties of honey-rich powder. Food Bioprod. Process. 2019, 115, 78-86. [CrossRef]

20. Kachel-Jakubowska, M.; Matwijczuk, A.; Gagoś, M. Analysis of the physicochemical properties of post-manufacturing waste derived from production of methyl esters from rapeseed oil. Int. Agrophys. 2017, 31, 175-182. [CrossRef]

21. Budziak, I.; Arczewska, M.; Kamiński, D.M. Formation of prenylated chalcone xanthohumol cocrystals: Single crystal X-Ray diffraction, vibrational spectroscopic study coupled with multivariate analysis. Molecules 2019, 24, 4245. [CrossRef]

22. Yu, P. Applications of hierarchical cluster analysis (CLA) and principal component analysis (PCA) in feed structure and feed molecular chemistry research, using synchrotron-based Fourier transform infrared (FTIR) microspectroscopy. J. Agric. Tood Chem. 2005, 53, 7115-7127. [CrossRef] [PubMed]

23. Matwijczuk, A.; Oniszczuk, T.; Matwijczuk, A.; Chruściel, E.; Kocira, A.; Niemczynowicz, A.; Wójtowicz, A.; Combrzyński, M.; Wiacek, D. Use of FTIR Spectroscopy and Chemometrics with Respect to Storage Conditions of Moldavian Dragonhead Oil. Sustainability 2019, 11, 6414. [CrossRef]

24. Granato, D.; Santos, J.S.; Escher, G.B.; Ferreira, B.L.; Maggio, R.M. Use of principal component analysis (PCA) and hierarchical cluster analysis (HCA) for multivariate association between bioactive compounds and functional properties in foods: A critical perspective. Trends Food Sci. Technol. 2018, 72, 83-90. [CrossRef]

25. Rabiej, M. Application of the particle swarm optimization method for the analysis of wide-angle X-ray diffraction curves of semicrystalline polymers. J. Appl. Cryst. 2017, 50, 221-230. [CrossRef]

26. Shi, R.; Zhang, Z.; Liu, Q.; Han, Y.; Zhang, L.; Chen, D.; Tian, W. Characterization of citric acid/glycerol co-plasticized thermoplastic starch prepared by melt blending. Carbohydr. Polym. 2007, 69, 748-755. [CrossRef]

27. Oniszczuk, T.; Combrzyński, M.; Matwijczuk, A.; Oniszczuk, A.; Gładyszewska, B.; Podleśny, J.; Czernel, G.; Karcz, D.; Niemczynowicz, A.; Wójtowicz, A. Physical assessment, spectroscopic and chemometric analysis of starch-based foils with selected functional additives. PLoS ONE 2019, 14, e0212070. [CrossRef]

28. Derjaguin, B.V.; Muller, V.M.; Toropov, Y.P. Effect of contact deformations on the adhesion of particles. J. Colloid Interface Sci. 1975, 53, 314-326. [CrossRef]

29. Ma, X.F.; Yu, J.; Wan, J. Urea and ethanolamine as a mixed plasticizer for thermoplastic starch. Carbohydr. Polym. 2006, 64, 267-273. [CrossRef]

30. Lancuški, A.; Ammar, A.A.; Avrahami, R.; Vilensky, R.; Vasilyev, G.; Zussman, E. Design of starch-formate compound fibers as encapsulation platform for biotherapeutics. Carbohydr. Polym. 2017, 158, 68-76. [CrossRef]

31. Kaushik, A.; Singh, M.; Verma, G. Green nanocomposites based on thermoplastic starch and steam exploded cellulose nanofibrils from wheat straw. Carbohydr. Polym. 2010, 82, 337-345. [CrossRef]

32. Shujun, W.; Jiugao, Y.; Jinglin, Y. Preparation and characterization of compatible thermoplastic starch/polyethylene blends. Polym. Degrad. Stabil. 2005, 87, 395-401. [CrossRef]

33. Kizil, R.; Irudayaraj, J.; Seetharaman, K. Characterization of irradiated starches by using FT-Raman and FTIR spectroscopy. J. Agric. Food Chem. 2002, 50, 3912-3918. [CrossRef] [PubMed]

34. Chen, Y.; Cao, X.; Chang, P.R.; Huneault, M.A. Comparative study on the films of poly (vinyl alcohol)/pea starch nanocrystals and poly (vinyl alcohol)/native pea starch. Carbohydr. Polym. 2008, 73, 8-17. [CrossRef]

35. Barbosa, J.V.; Martins, J.; Carvalho, L.; Bastos, M.M.S.M.; Magalhães, F.D. Effect of peroxide oxidation on the expansion of potato starch foam. Ind. Crop. Prod. 2019, 137, 428-435. [CrossRef]

36. Kupryaniuk, K.; Oniszczuk, T.; Combrzyński, M.; Czekała, W.; Matwijczuk, A. The Influence of Corn Straw Extrusion Pretreatment Parameters on Methane Fermentation Performance. Materials 2020, 13, 3003. [CrossRef]

37. Rubens, P.; Snauwaert, J.; Heremans, K.; Stute, R. In situ observation of pressure-induced gelation of starches studied with FTIR in the diamond anvil cell. Carbohydr. Polym. 1999, 39, 231-235. [CrossRef] 